\title{
A Comparative Study on the Material Application of Traditional Sculpture and Contemporary Sculpture
}

\author{
Jin Luo \\ Ceramics Academy of Fine Arts, Jingdezhen Ceramic Institute \\ Jingdezhen City, Jiangxi Province, China \\ Email: 411966472@qq.com
}

Keywords: Traditional sculpture; Contemporary sculpture; Material application; Comparative study

\begin{abstract}
Sculpture belongs to one of the art expression form, in the process of long-term development, it has formed a relatively perfect development system. It is also advancing with the times in the application of materials. The traditional sculpture is relatively simple in the use of materials, more emphasis are put on narrative in the art artistic modeling, pay attention to highlight the body aesthetics, hidden materials, while contemporary sculpture is different from it, more emphasis are put on the return of artistic language and materials, beyond the artistic narrative. To a certain extent, the material is the most important factor in the composition of sculpture, belongs to the material premise and the basic elements, the use of comprehensive materials liberate the artist's ideas to a great extent, more able to express the free personality of the creator, so that promoting the art of sculpture becoming the main art form of expressing ideas. This paper focuses on the comparative study of the use of traditional sculpture and contemporary sculpture materials, and further elaborates the important basis of material selection.

From the analysis of physical level, sculpture is a three-dimensional space objects, and from the spiritual level, it belongs to the artist's concept, as well as substantive spiritual beliefs. Sculpture use the clearest way to effectively present the spirit concept of the author. Material is an important component of sculpture, belongs to its language form of expression, reflecting the level of use of sculpture art material in the value. In this paper made a comparative analysis on the application of materials of traditional sculpture and contemporary sculpture, and explored the importance of material selection, and then promote relative people could apply material to the creative process of sculpture more clearly and rationally.
\end{abstract}

\section{The Elaboration of Traditional Sculpture and Modern Sculpture}

\section{Analysis on the Use of Sculpture Art Material}

In the long process of development, traditional sculpture has formed their own unique style of flavor, and played a very crucial role in the historical and cultural heritage, it shows a variety of diversity in the expression form. In the aspect of material performance, the Western traditional sculpture used the marble, as well as the bronze highlight the oriental characteristics, but also contained the African culture pottery and wood, in a sense, it is a typical sculpture material. It is noteworthy that the traditional sculpture material screening is relatively rich, but in sculpture creation process, the artist needs to think about the following content, that is, how to do sculpture, rather than put more energy on what materials could be used, the situation of the mixed use of multi-material is basically rare, this sculpture is almost very rare. But for artists and craftsmen, in the choice of materials, they need to take a number of factors into account, such as regional materials, so that it will be more convenient, but also the plasticity of the material is strong, and for some of the highly practical sculpture, they are mainly used for worship and witchcraft, with practical reference significance to some extent.

\section{Introduction to Traditional Sculpture}

Traditional sculpture formed their own unique system and characteristics in the development of the era, such as: Western sculpture art, in the development process, is essentially different from regional sculpture, which shows the following obvious features: narrative, 
reproducibility. Classical sculpture pay more attention to reason and order, symmetry and proportion, more concerned about the creation of harmonious beauty, such a sculpture has a simple and elegant beauty; while for romantic sculpture, then pay attention to the spirit of freedom, spectacular momentum, with a certain of the rebellious sense, but whether it is romantic or classical, are basically using realistic expression techniques, so as to achieve good expression. The above specific image, to some extent, has a traditional sculpture eternal sense, so the traditional sculpture is more simply in the material screening, and using pure and solid texture of the material. For example: the sculptor Rodin, the more emphasis are put on stone solid and bronze texture, in his inherited work, we could not find sculpture with other types of materials.

\section{The Introduction of Contemporary Sculpture}

For traditional sculpture works, mainly treating the work form as the purpose, and then screen the material, and contemporary sculpture works are different, pay more attention to publicity and material display, highlight the material characteristics, while integrating the artist's personality and ideas. Contemporary sculpture is more focusing on the use of innovative elements, in the creative process, to highlight their own personality and ideas. With the continuous development of the times, in the whole process, to promote the continuous collision of Chinese and Western, and for the sculpture material language, continue to enrich in the actual process of integration. Looking at the current sculpture works, many materials can be effectively used in contemporary sculpture. Such as glass, plastic, paper, etc., these elements become the important component of contemporary sculpture, thus forming a unique art and culture in this period.

\section{The use and Selection of Materials of Traditional Sculpture and Modern Sculpture}

\section{Changes in Artistic Trends}

In the 1960s, the classically traditional art gradually dies, specifically, covered by some innovative and abstract style of art style. In the course of the development of classical art, the art form occupying the same position with painting has experienced a rapid development in this period, that is, the evolution of sculpture style. From cubism, to abstractism, then to compositionism, the choice of sculpture material has different characteristics in different periods, especially in the promotion by artist's mind, showed in the form of "flourishing", not impossible, but only can not think of it. With the development of different trends in art, which led to the development of sculpture showing a variety of trends, such as: concept art, scrap sculpture, package sculpture, finished sculpture, etc., are on stage in the name of the sculpture. From the overall point of view, the use of integrated materials has epoch-making significance, which makes the concept of sculpture fuzzy, while sculpture as the art form going through the long-term development will face the concept of replacement.

\section{The Choice and Use of Materials}

With the development and changes of political economy, people's thinking and even ideas have undergone tremendous changes to make it more aesthetic sense, the reason why the above situation appears are as follows: First is the economic development, high-tech products are showing the rapid changes to promote the use of high-tech materials and new technology to bring great challenges to sculpture art; second is the promotion of substance level, the pace of people's life become faster, to prompt the change of life concept to a certain extent; the classical beauty has been unable to attract the attention of the public, especially the demand for beauty, people also put forward a higher demand for sculpture art, must be a strong sense of excitement to meet the psychological needs of the public, In order to bring the audience the relax physically and mentally, and then be able to let people liberate from the real pressure. So for the sculpture material, the range of the choice is relatively wide, rather than confined to the traditional sculpture material, many other elements is also reflected in contemporary sculpture, such as: water, light, gas, etc., to promote diversification of contemporary sculpture in the screening of material.

\section{Sculpture Material Prolongation}

The so-called sculpture material prolongation, not only reflects the material prolongation, but also in the non-material level, such as: ideas, language, words and so on. For example: taking the 
"Three Chairs" as an example, the sensation caused by this work can not be imagined at this stage when the people is very indifferent of the works material, and include controversial and

shock, works mainly include the following aspects: chair, text, photos, although it looks casual, but it is imaginative. There are some artists, selecting metal materials to carry out sculpture creation, but under the guidance of the new creative ideas, coupled with the promotion of modeling technology, to promote the presence with a strong sense, not just the environment embellishment. For example: Sculptor Richard - Serra, his choice of materials in the sculpture is copper, at the same time, also covers other metals, but his works have their own characteristics, compared with the traditional sculpture casting, it has the difference essentially, more emphasizing on minimalism, in virtue of a lot of metal elements, to promote their works show a grand atmosphere, rich sense of weight. The reason why there will be the feeling is that it related with the author's own design points and lines, surface and other shapes, as well as the volume of sculpture, but the sense of weight of the metal material in the actual application process can not be ignored, could say it is the core of the work. The public shuttle in this huge building, will inevitably feel the taste of metal cold, with a certain texture of the oppression and push, more deeply rooted in people's heart.

For example: Richard Sulla's "Sloping Arc", which is representative of the simple curved metal shape, can glance all simply one time, but can not let people stop at a glance, from which we can see the shock effect brought by the works. The work was originally stored in the Federal Square in New York, the space span is relatively high, running through the square at both ends, its curvature direction is just the opposite to radian direction of square tiles, and its own existence of slightly rusty texture lighten the most out of sense of metal weight, as well as a sense of oppression, but it can also give people shines, the outer contour is relatively sharp, which is unique characteristics of the metal texture. From which, we can see the greatness of the work, but it still can not get the support of the people, and ultimately move out of Times Square. This metal wall is relatively deep, the protest is because of being unable to get more psychological feelings.

\section{More Abundant of the Sculpture Language by Promotion}

For the above materials, its application in the sculpture has a more realistic significance, sculpture language become much richer. Material is an indispensable part for the artist's sculpture creation. The typical representative is the thought and the concept of the media, not only has the value of independence and innovation. Artists must analyze the comprehensive materials effectively, interpreting the works by the images in the works, further highlight the unique charm of the material language, and grasp the attractiveness of the material, which also makes the application of traditional materials toward a better direction. The involvement of comprehensive materials makes sculpture more creative, especially in modeling, the most important thing is to integrate into modern high-tech, no longer stay in the traditional performance techniques. No matter that it is a single material, or a variety of materials, driven by the new concept, the artist needs to use new materials and technical means to constantly enrich the artistic expression content, more highlight the personality and ideas. It can be seen that the application of composite materials in sculpture art has made its subjective performance more vivid and innovative in terms of performance techniques, thus giving new forms of sculpture development. Rich sculpture language can make the sculpture more attractive to the public, especially the development of art in the new era, thus promoting the development of sculpture art is much closer to the requirements of the times, in the language performance art, it can be more in line with the current artistic needs, prompt art language expression more vivid and specific.

\section{Conclusion}

To sum up, sculpture art form their own unique artistic style in the development trend of the times, and with the development of the times, it shows a different artistic expression, in which the most important thing is the use of materials that play a good promotion effect on the development of the sculpture. For artists and craftsmen, in the choice of materials, they need to take a number of factors into account, such as regional materials to bring more convenient routine, besides, the plasticity of 
the material is much stronger, while for some of the highly practical sculpture, applied in the sacrifice and witchcraft, with practical reference significance to a certain extent. this paper interpreted the comparative study of the traditional sculpture and contemporary sculpture materials, from different periods to carry out effective analysis for specific circumstances, which highlights the screening criteria and requirements of sculpture materials in the different periods, and it is necessary to introduce new materials and new technologies into the creative process, to promote the development of sculpture art more in line with the needs of the times to accelerate its rapid development.

\section{References}

[1] W.J. Shao. Discussion on the misunderstanding of the traditional material in the contemporary sculpture [J]. Popular arts, 2013, 04: 277.

[2] W.J. Shao. Traditional materials in contemporary sculpture creation [J]. Popular Arts, 2013, 12: 121-122.

[3] W.A. Luo, Liang Juan. Comparison of traditional sculpture and contemporary sculpture materials [J]. Fine Arts Education Research, 2013, 13: 103-104.

[4] J. Li. Chinese contemporary sculpture material language innovation techniques [J]. Sculpture, 2015, 1: 60-61.

[5] B. Gong. Visual attributes conversion between virtual sculpture and physical sculpture [J]. Art Observation, 2014, 4: 128.

[6] Y.Y. Yin. From copy to creation - Taking the Buddhist statues of Tang Dynasty as an example [J]. Arts \& Science, 2014, 10: $107+105$.

[7] H.Q. Xie. Transmutation in the inheritance-Analysis of the style and aesthetic characteristics of Jingdezhen Contemporary Academy Ceramic Sculpture [J]. Fine Arts Education Research, 2016, 8: 34-35.

[8] X. Li. Legend of freehand and contemporary feelings-Chinese freehand sculpture theory [J]. National Art Research, 2016, 2: 228-233. 